\title{
Suppressive Effect of Tetrahydrobiopterin on L- $\beta$-(3,4-Dihydroxyphenyl) alanine-Induced Cytotoxicity in PC-12 Cells
}

\author{
Shuji Kojima ${ }^{\S}$, Hiroshi Kugenuma, Sayaka Oyobe, Hiroyuki Iizuka and Masahiko Ikekita \\ Research Institute for Biological Sciences, Science University of Tokyo, 2669 Yamazaki, Noda, \\ Chiba 278, Japan
}

(Received September 20, 1997)

\begin{abstract}
Summary
We examined the inhibitory effect of tetrahydrobiopterin $\left(\mathrm{BPH}_{4}\right)$ on $\mathrm{L}-\beta$ - $(3,4$-dihydroxyphenyl $)$ alanine (DOPA)-induced cytotoxicity in PC-12 cells. First in vitro inhibitory efficacy of BPH4 on lipid peroxidation induced by $\mathrm{Fe}^{3+}$-DOPA complex was confirmed by using PC-liposomes. $\mathrm{Fe}^{3+}$-DOPA complex at $50 \mu \mathrm{M}$ caused drastic lipid peroxidation, which was significantly inhibited by $\mathrm{BPH}_{4}$ in a dose-dependent manner. Next, we confirmed the in vitro potency of BPH4 in cultured PC-12 cells. Fe ${ }^{3+}$-DOPA complex exerted time-and dose-dependent cytotoxicity, which was also dose-dependently inhibited by $\mathrm{BPH}_{4} \mathrm{Pos}^{-}$ sessed almost the same potency as deferoxamine and $\alpha$-tocopherol. We also examined the cytotoxicity of DOPA itself. A higher dose of DOPA $(250 \mu \mathrm{M})$ was necessary to afford the same cytotoxic potency towards PC- 12 cells as that of $\mathrm{Fe}^{3+}$-DOPA complex $(50 \mu \mathrm{M})$. The toxicity was essentially abolished by SOD and $\mathrm{Bl}_{4} \mathrm{H}_{4}$, and ameliorated by catalase. However, deferoxamine did not modify the toxicity. In conclusion, $\mathrm{BPH}_{4}$ protects both PC-liposomes and $\mathrm{PC}-12$ cells from damage induced by DOPA with and without ferric ion, and may inhibit the degeneration of dopamine neurons through its antioxidative activity.
\end{abstract}

Key words : Tetrahydrobiopterin, DOPA, Cỵtotoxicity, PC-12 cells

\section{Introduction}

$5,6,7,8$-Tetrahydrobiopterin $\left(\mathrm{BPH}_{4}\right)$, which is biosynthesized from guanosine triphosphate (GTP) $(1,2)$, acts as a cofactor for phenylalanine, tyrosine and tryptophan hydroxylases (3-5). It plays an important role in regulating the in vivo activities of tyrosine and tryptophan hydrolases, which are the rate-limiting enzymes in the biosynthesis of the catecholamines and serotonin, respectively. $\mathrm{BPH}_{4}$ also has a regulatory role in cytokine-induced $\mathrm{NO}$ biosynthesis in various cells (6-9).

§ Author to whom correspondence should be addressed.
Parkinsonism is pathologically manifested as a premature degeneration of dopamine neurons, leading to depletion of dopamine, and it has been suggested that the possible elevation of tyrosine hydrolase activity in surviving dopamine neurons by $\mathrm{BPH}_{4}$ administration may provide a therapeutic means of increasing striatal synaptic dopamine (1012). It has been speculated that the degeneration of dopamine neurons in Parkinson's disease is induced, at least in part, by active oxygen radicals (13, 14).

We have recently observed strong antioxidative activity of $\mathrm{BPH}_{4}$, and suggested a possible new function of this compound as an endogenous an-

Pteridines $/$ Vol. $8 /$ No. 1 
tioxidant $(15,16)$. Based on the hypothesis that degeneration of neurons is caused by active oxygen radicals, $\mathrm{BPH}_{4}$ has been suggested as a potential therapeutic agent for Parkinson's disease on the basis of not only its potency to increase the supply of dopamine as a cofactor for hydrolases, but also its antioxidative efficacy.

In this study, suppression of DOPA-induced cytotoxicity by $\mathrm{BPH}_{4}$ was investigated in the $\mathrm{PC}-12$ cell line (derived from rat adrenal medulla), which has dopamine-synthesizing, -storage, and -releasing potentials similar to those of neurons.

\section{Materials and Methods}

\section{Materials}

RPMI 1640 was purchased from Nissui Co., Ltd., Tokyo, Japan. Fetal bovine serum (FBS) was from BIO Whittaker Co., Maryland, U.S.A.

Horse serum (HS) was from Gibco Lab., Germany. $\beta-\mathrm{NADH}$ was obtained from Oriental Yeast Co. Ltd., Tokyo Japan. Superoxide dismutase (SOD, 3900 units/mg), catalase (7500 units/ $\mathrm{mg}), \alpha$-tocopherol acetate $(\alpha$-TP), sodium pyruvate, phosphatidylcholine (PC) from egg yolk, L- $\beta$-(3,4-dihydroxyphenyl)alanine (L-DOPA), ferrous chloride, and adenosine 5'-diphosphate monosodium salt (ADP) were obtained from Wako Chemicals Co. Ltd., Tokyo, Japan. Kanamycin sulfate was from Meiji Seika Co., Ltd., Tokyo, Japan. Deferoxamine (DF) was from Nippon Ciba Geigy Co. Ltd., Tokro, Japan. $\alpha$-Phenvl-N-t-butylnitrone (PBN) was obtained from Aldrich, Tokyo, Japan. 5,6,7,8Tetrahydrobiopterin $\left(\mathrm{BPH}_{4}\right)$ was a gift from Suntory Co. Ltd., Tokyo, Japan.

Inhibitory effect of $\mathrm{BPH}_{4}$ on autoxidation of PC-liposomes

Phosphatidylcholine (PC) from turkey egg yolk $(100 \mathrm{mg})$ was dissolved in chloroform: methanol (2:1) solution, and evaporated under nitrogen gas to form a thin layer on the wall of a glass vessel. Phosphate-buffered saline (PBS) was then added and agitated vigorously for $10 \mathrm{~min}$ to obtain a liposome suspension. One $\mathrm{ml}$ of the solution was incubated with $\mathrm{Fe}^{3+}$. DOPA complex in the presence or absence of $\mathrm{BPH} 4$ or another scavenger at $37^{\circ} \mathrm{C}$. An aliquot of the liposomal preparation $(0.2$ $\mathrm{ml}$ ) was removed at intervals and boiled for 40 $\mathrm{min}$ in $1 \mathrm{ml}$ of $15 \%$ trichloroacetic acid and $0.25 \%$ thiobarbituric acid. It was cooled, then $4 \mathrm{ml}$ of butanol was added. The mixture was vortexed vig- orously and centrifuged at $3,000 \mathrm{rpm}$ for $30 \mathrm{~min}$ The absorbance of the butanol layer was measured at $532 \mathrm{~nm}$ to estimate the content of malondialdehyde (MDA). $\mathrm{Fe}^{3+}$-DOPA complex was prepared according to the method of Sugioka and Nakano (17) with a slight modification.

\section{Tissue culture}

PC-12 cell line was obtained from Riken Cell Bank, Tsukuba, Japan. The cells were routinely cultured in RPMI 1640 medium supplemented with $10 \%$ HS and $5 \%$ FBS at $37^{\circ} \mathrm{C}$ in an atmosphere of $95 \% \mathrm{O}_{2}$ and $5 \% \mathrm{CO}_{2}$. The cells suspended in the medium were seeded into 24 -well plates at a concentration of $1 \times 10^{6}$ cells per dish and were cultured for $24 \mathrm{hr}$. $\mathrm{Fe}^{3+}$-DOPA, DOPA, $\mathrm{BPH} 4$ and other scavengers including SOD (1000 $\mathrm{U} / \mathrm{ml})$, catalase $(200 \mathrm{U} / \mathrm{ml}), \mathrm{PBN}(100 \mu \mathrm{M}), \mathrm{DF}$ $(100 \mu \mathrm{M})$, mannitol (MAN, $10 \mu \mathrm{M})$ and $\alpha$-TP $(100 \mu \mathrm{M})$, dissolved in the medium, were then added as appropriate and incubation was continued in a $\mathrm{CO}_{2}$ incubator.

\section{Assay of lactate dehydrogenase ( $L D H)$}

LDH released into the medium from $\mathrm{PC}-12$ cells was assayed as a marker of cell damage. An aliquot of the supernatant of the cultured medium was collected at each time interval and subjected to LDH assay with LDH CII-Test Wako (Wako Chemicals Co., Ltd., Tokyo, Japan). The activity was expressed as Wroblewski units $/ \mathrm{ml}$ medium.

\section{Assay of lipid peroxides}

After incubation, lipid peroxides in the cells were measured by a thiobarbituric acid procedure according to the method of Gavino et al. (18). The concentration of lipid peroxides was expressed as nmol of malondialdehyde (MDA) per dish.

\section{Statistical analysis}

Statistical significance was determined by Student's $t$ test for the comparison between two groups or two way repeated measures analysis of variance (ANOVA) and Dunnett's tests for multiple comparison where appropriate. The criterion of significance was taken as $P<0.05$.

\section{Results}

Oxidation of $\mathrm{PC}$-liposomes and inhibition by $\mathrm{BPH}_{4}$

As shown in Figure 1, significant increases of Pteridines $/$ Vol. $8 /$ No. 1 


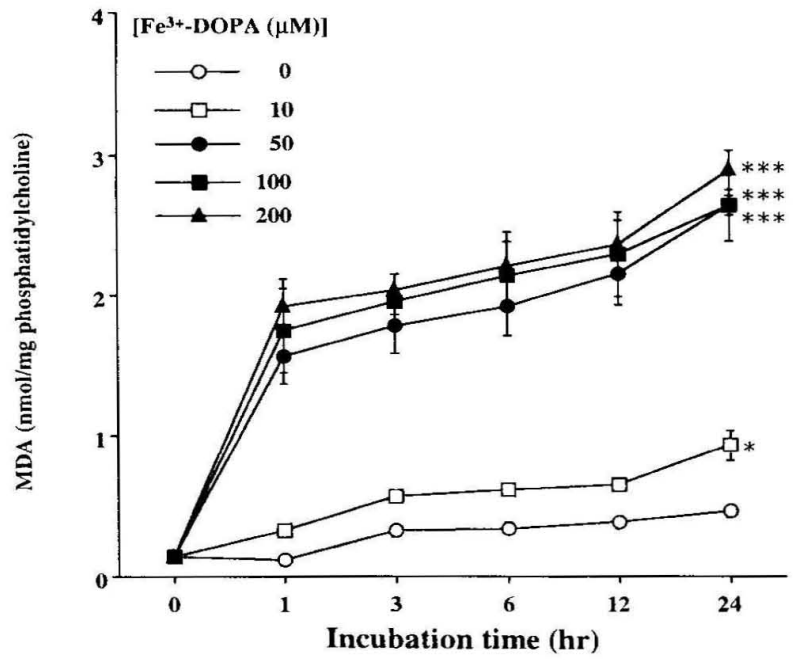

Figure 1. Time courses of the effect of $\left.\mathrm{Fe}^{3 .}-1\right) O P A$ complex on the lipid peroxidation of PC-liposomes. PC-liposomes suspended in phosphate-buffered saline were incubated with $10,50,100$, and $200 \mu \mathrm{M} \mathrm{Fe} \mathrm{F}^{3-}$-DOPA complex for $24 \mathrm{hr}$. Aliquots of sample were collected at intervals and subjected to lipid peroxide assay. Lipid peroxides are represented as the content of malondialdehyde (MDA). Each value is the mean \pm S.F.M. of 3 independent assays. Significantly different from the normal con$\operatorname{trol}(0 \mu \mathrm{M}):{ }^{*} \mathrm{P}<0.05,{ }^{* \star *} \mathrm{P}<0.001$.

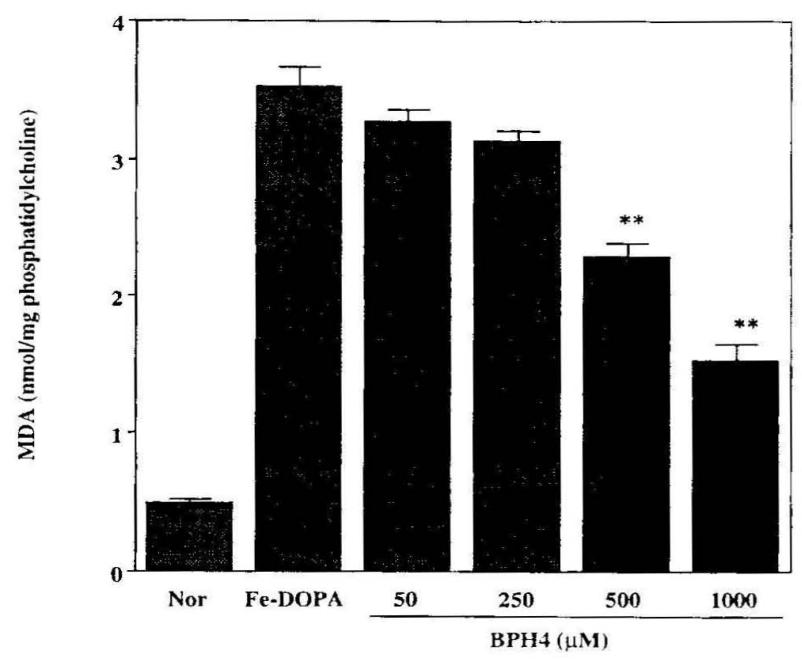

Figure 2. Effects of $\mathrm{BPH}_{4}$ on the lipid peroxidation of PC-liposomes induced by $\mathrm{Fe}^{3+}$-DOPA complex. PC-liposomes suspended in phosphate-buffered saline were incubated with $50 \mu \mathrm{M} \mathrm{Fe} \mathrm{Fe}^{3+}$-DOPA complex in the presence of $\mathrm{BPH}_{4}$ for $3 \mathrm{hr}$, and lipid peroxide was assayed. Lipid peroxides are represented as the content of malondialdehyde (MDA). Each value is the mean \pm S.E.M. of 3 independent assays. "Nor" indicates the control without $\mathrm{Fe}^{3+}$-DOPA. Significantly different from $\mathrm{Fe}^{3+}$-DOPA complex-treated group: ${ }^{\star \star} \mathrm{P}<0.01$.

MDA content were observed at concentrations of more than $50 \mu \mathrm{M} \mathrm{Fe} \mathrm{Fe}^{3+}$-DOPA complex, without
Table 1. Inhibitory potency of $\mathrm{BPH}_{4}$ and other scavengers against lipid peroxidation of $\mathrm{PC}$-liposomes induced by $\left.\mathrm{Fe}^{\mathrm{i}}-1\right) \mathrm{OPA}$

\begin{tabular}{lc}
\hline \hline Scavenger & $50 \%$-inhibitory conc. $\left(\mathrm{IC}_{50, \mu \mathrm{N}}\right)$ \\
\hline $\mathrm{BPH}_{+}$ & 650 \\
$\mathrm{DF}$ & 240 \\
$\alpha-\mathrm{TP}$ & 120 \\
SOD & - \\
catalase & - \\
PBN & - \\
MAN & - \\
\hline
\end{tabular}

$\mathrm{BPH}_{4}$, 5,6,7,8-tetrahydrobiopterin; DF, deferoxamine; $\alpha$-TP, $\alpha$-tocopherol; SOD, superoxide dismutase; PBN, $\alpha$-phenyl-N-t-butylnitone; MAN, mannitol. -, no potency.

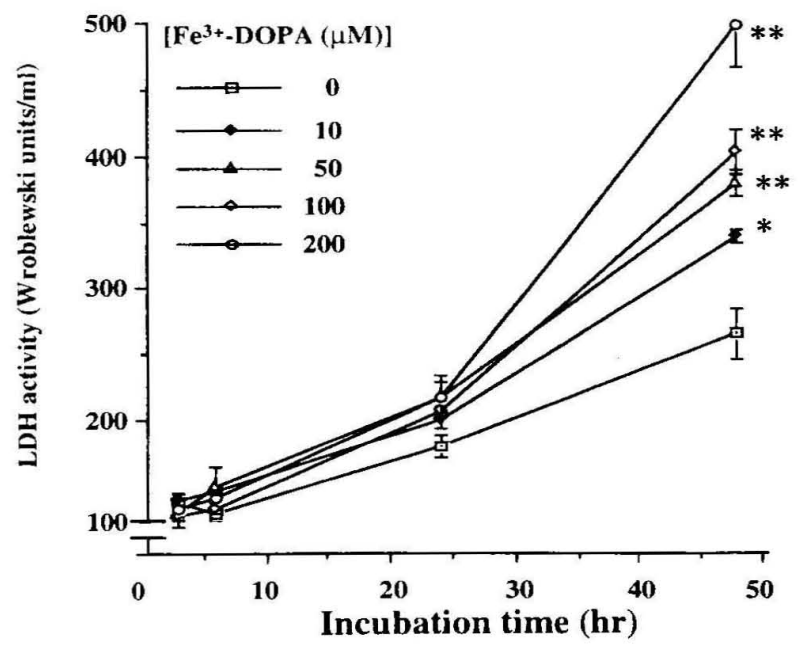

Figure 3. Time courses of the effect of $\mathrm{Fe}^{3+}$-DOPA complex on $\mathrm{L} . \mathrm{DH}$ release by $\mathrm{PC}-12$ cells as a mark of cell damage. The cells were incubated with $10,50,100$, and $200 \mu \mathrm{M} \mathrm{Fe}-$ DOPA complex for $48 \mathrm{hr}$. Aliquots of the medium were collected at intervals and subjected to LDH assay. LDH activity is represented as Wroblewski units $/ \mathrm{ml}$ medium. Each value is the mean \pm S.E.M. of 4 independent assays. Significantly different from the nor mal control $(0 \mu \mathrm{M}):{ }^{\star} \mathrm{P}<0.05,{ }^{\star \star}{ }^{\star} \mathrm{P}<0.01$.

apparent dose-dependency. The content increased in a time-dependent manner, reaching a plateau at about $3 \mathrm{hr}$. We then examined the effect of BPH4 on the elevation of lipid peroxides in PC-liposomes treated with $50 \mu \mathrm{M} \mathrm{Fe}{ }^{3+}$-DOPA for $3 \mathrm{hr}$. The elevation was suppressed by $\mathrm{BPH}_{4}$ in a dose-dependent manner at concentrations ranging from 50 to 1000 $\mu \mathrm{M}$ (Figure 2). The efficacy of $\mathrm{BPH}_{4}$ was compared with those of other scavengers, i.e., DF and $\alpha$-TP. As shown in Table 1 , the $50 \%$-inhibitory concentrations $\left(\mathrm{IC}_{50}\right)$ for $\mathrm{BPH}_{4}, \mathrm{DF}$ and $\alpha$-TP were $650 \mu \mathrm{M}, 240 \mu \mathrm{M}$ and $120 \mu \mathrm{M}$, respectively. SOD $(1000 \mathrm{U} / \mathrm{ml})$, catalase $(200 \mathrm{U} / \mathrm{ml})$, PBN $(100$ $\mu \mathrm{M})$, and MAN (10 mM) were ineffective. 


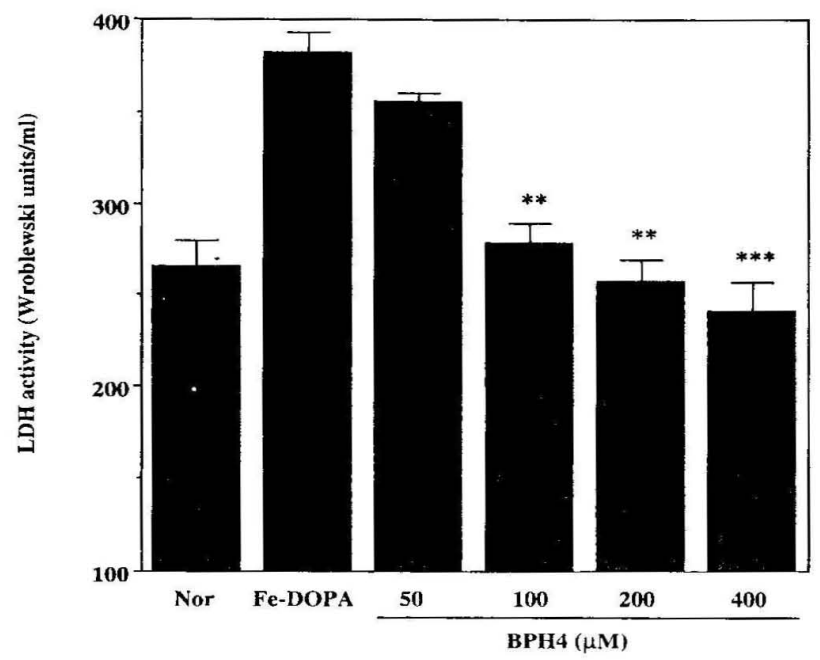

Figure 4. Effects of $\mathrm{BPH}_{4}$ on the elevation of $\mathrm{LDH}$ activity induced by $\mathrm{Fe}^{3+}$-DOPA complex in cultured PC-12 cells. The cells were incubated with $50 \mu \mathrm{M} \mathrm{Fe} \mathrm{Fe}^{32}$-DOPA complex in the presence of $\mathrm{BPH}_{4}$ for $48 \mathrm{hr}$, and $\mathrm{LDH}$ activity was assayed. $\mathrm{LDH}$ activity is represented as Wroblewski units $/ \mathrm{ml}$ medium. Each value is the mean \pm S.E. $M$. of 4 independent assays. "Nor" indicates the control without $\mathrm{Fe}^{3+}$-DOPA or $\mathrm{BPH}_{4}$. Significantly different from $\mathrm{Fe}^{3+}$-DOPA complex-treated group: ${ }^{\star \star} \mathrm{P}<0.01,{ }^{\star \star} \mathrm{P}<0.001$.

Elevation of $\mathrm{LDH}$ activity induced by $\mathrm{Fe}^{3+}$-DOPA in $\mathrm{PC}-12$ cells

Release of LDH, a marker enzyme for cytotoxicity, from PC-12 cells was assessed at different concentrations of $\mathrm{Fe}^{3+}$-DOPA complex. Namely, PC12 cells were incubated with $10,50,100$ and 200 $\mu \mathrm{M} \mathrm{Fe}{ }^{3+}$-DOPA complex and the release of $\mathrm{LDH}$ from the cells was assayed as a function of time for $48 \mathrm{hr}$. As shown in Figure 3, no significant increase of LDH activity was obscred $24 \mathrm{hr}$ after the start of treatment with $\mathrm{Fe}^{3+}$-DOPA complex at any dose examined. However, significant increases of $\mathrm{LDH}$ activity were observed at $48 \mathrm{hr}$, though the LDH activity of control cells was also increased at $48 \mathrm{hr}$-incubation. Based on these data, we fixed the concentration of $\mathrm{Fe}^{3+}$-DOPA complex at $50 \mu \mathrm{M}$ for further experiments.

\section{Effect of $\mathrm{BPH}_{4}$ on $\mathrm{Fe}^{3+}$-DOPA-induced cytotoxicity in $\mathrm{PC}-12$ cells}

The effect of $\mathrm{BPH}_{4}$ on the elevation of $\mathrm{LDH}$ activity at $48 \mathrm{hr}$ after treatment of PC-12 cells with $\mathrm{Fe}^{3+}$-DOPA $(50 \mu \mathrm{M})$ was examined. As can be seen in Figure 4, the $\mathrm{Fe}^{3+}$-DOPA complex-induced elevation of $\mathrm{LDH}$ activity was inhibited by $\mathrm{BPH}_{4}$ in a dose-dependent manner at concentrations ranging from 50 to $400 \mu \mathrm{M}$. $\mathrm{BPH}_{4}$ itself

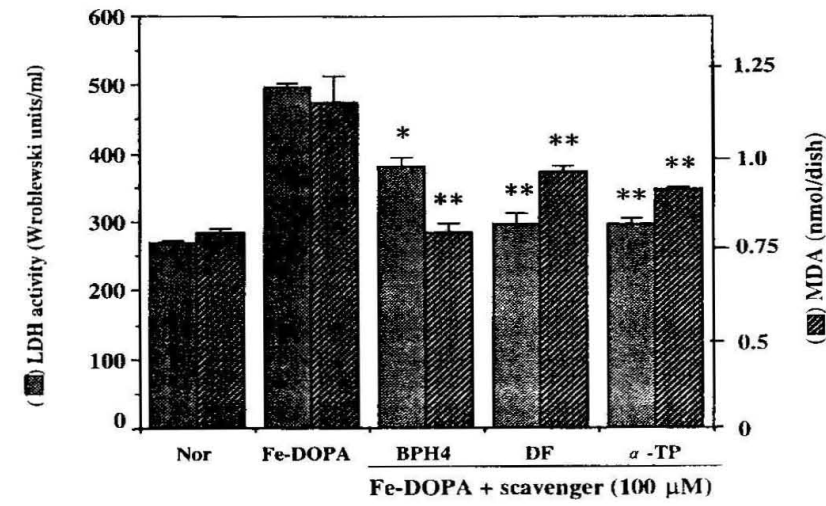

Figure 5. Effect of $\mathrm{BPH}_{4}$ and other scavengers on the elevation of LDH activity and lipid peroxides induced by $\mathrm{Fe}^{3+}$-DOPA complex in cultured PC-12 cells. A fixed concentration $(100 \mu \mathrm{M})$ of $\mathrm{BPH}_{4}$ or another scavenger was added to the medium simultaneously with $50 \mu \mathrm{M}$ $\mathrm{Fe}^{3+}$-DOPA complex, and the mixture was incubated for $48 \mathrm{hr}$. $\mathrm{LDH}$ activity in the medium and lipid peroxides in the cells were assayed. LDH activity and lipid peroxides content are expressed in Wroblewski units $/ \mathrm{ml}$ and as malondialdehyde content per mg protein (MDA $/ \mathrm{mg}$ protein), respectively. $\mathrm{BPH}_{4}, 5,6,7,8$-tetrahydrobiopterin; DF, deferoxamine; $\alpha$-TP, $\alpha$-tocopherol. Each value indicates the mean \pm S.E.M. of 4 determinations. "Nor" indicates the control without $\mathrm{F}^{3+}$-DOPA or scavenger. Significantly different from $\mathrm{Fe}^{3-}$-DOPA complex -treated group: ${ }^{\star} \mathrm{P}<0.05,{ }^{\star \star} \mathrm{P}<0.01$

did not increase the release of LDH in the cultures. The potency of $\mathrm{BPH}_{4}$ was compared with those of other scavengers in terms of $\mathrm{LDH}$ activity and MDA content at a constant concentration of $100 \mu \mathrm{M}$. All of these scavengers significantly suppressed the elevations of both chemical markers induced by $\mathrm{Fe}^{3+}$-DOPA complex (Figure 5).

Effect of $\mathrm{BPH}_{+}$on DOPA-induced cytotoxicity in PC12 cells

We next investigated the effect of $\mathrm{BPH}_{4}$ on cytotoxicity induced by DOPA without $\mathrm{Fe}^{3+}$. The dose-dependence of the effect of DOPA on LDH release from PC-12 cells was preliminarily investigated (data not shown). The cells were incubated with $50,100,250$ and $500 \mu \mathrm{M}$ DOPA and the release of $\mathrm{LDH}$ in the culture medium was assayed as a function of time for $48 \mathrm{hr}$. No significant increase of LDH was observed at concentrations of less than $100 \mu \mathrm{M}$, but $\mathrm{LDH}$ was elevated at 250 and $500 \mu \mathrm{M}$. The activity at $24 \mathrm{hr}$ after treatment with $250 \mu \mathrm{M}$ DOPA was elevated to almost the same degree as with $50 \mu \mathrm{M} \mathrm{Fe}^{3+}$ DOPA complex. Thus, we examined the effect of $\mathrm{BPH}_{4}$ on the cytotoxicity induced by $250 \mu \mathrm{M}$ 


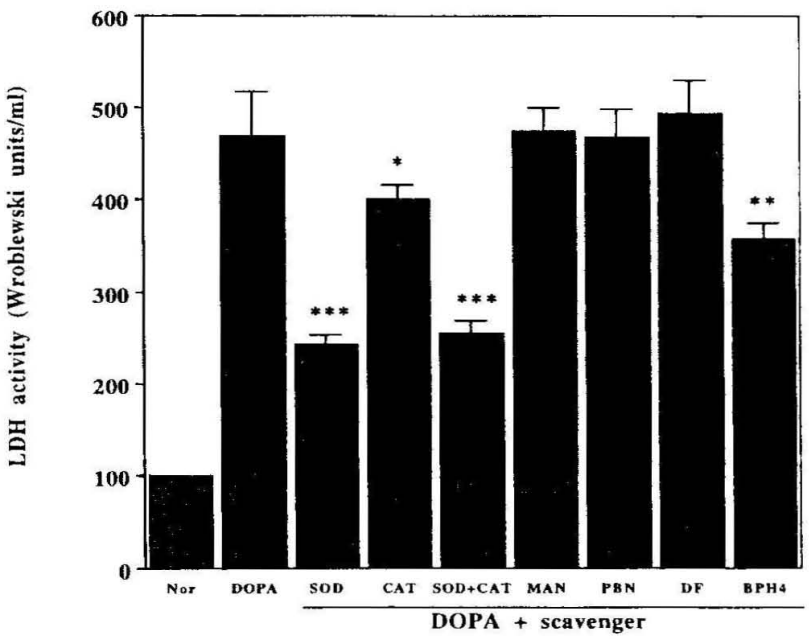

Figure 6. Effect of $\mathrm{BPH}_{4}$ and other scavengers on the elevation of LDH activity induced by DOPA in cultured PC. -12 cells. An appropriate concentration of $\mathrm{BPH}_{4}$ or another scavenger was added to the medium simultaneously with $250 \mu \mathrm{M}$ DOPA, and the mixture was incubated for $24 \mathrm{hr}$. L.DH activity was assayed. L.DH activity was expressed as Wroblewski units/ml. Each value indicates the mean \pm S.E.M. of 4 determinations. "Nor" indicates the control without DOPA or scavenger. Significantly different from DOPA-treated group: ${ }^{\star} \mathrm{P}<0.05$, ${ }^{*} \mathrm{P}<0.01,{ }^{* \star \star} \mathrm{P}<0.001 . \mathrm{BPH}_{4}, 5,6,7,8$-tetrahydrobiopterin $(100 \mu \mathrm{M})$; SOD, superoxide dismutase $(1000 \mathrm{U} / \mathrm{ml})$; CAT, catalase $(200 \mathrm{U} / \mathrm{ml})$; MAN, mannitol $(10 \mathrm{mM})$; PBN, $\alpha$-phenyl-N-t-butylnitrone $(100 \mu \mathrm{M}) ; \mathrm{DF}$, deferoxamine $(100 \mu \mathrm{M})$.

DOPA. As can been seen in Figure 6, $100 \mu \mathrm{M}$ $\mathrm{BPH}_{4}$ significantly suppressed the elevation of LDH activity induced by $250 \mu \mathrm{M}$ DOPA, as it did in the case of that induced by $50 \mu \mathrm{M} \mathrm{Fe} \mathrm{Fe}^{3 .}$. DOPA complex. SOD $(1000 \mathrm{U} / \mathrm{ml})$, a scavenger of $\mathrm{O}_{2}$, markedly reduced the elevation of $\mathrm{LDH}$ and catalase $(200 \mathrm{U} / \mathrm{ml})$, a scavenger of $\mathrm{H}_{2} \mathrm{O}_{2}$, showed partial inhibition, while MAN ( $10 \mathrm{mM}$ ) and PBN $(100 \mu \mathrm{M})$, scavengers of $\mathrm{OH}$ and $\mathrm{O}_{2}$, respectively, were ineffective. DF, a specific chelator of iron, had no effect under these conditions.

\section{Discussion}

The degeneration of nigro-strial dopaminergic neurons is considered to be a predominant pathogenetic factor in Parkinson's disease (19), and may involve oxygen free radicals such as $\mathrm{O}_{2}$, $\mathrm{OH}, \mathrm{H}_{2} \mathrm{O}_{2}$ and ${ }^{1} \mathrm{O}_{2}(13,14)$. This view is supported by the acceleration of lipid content (20) and increased iron level in the substantia nigra $(21,22)$ decreased peroxidase and catalase levels (23) and so on $(24,25)$. Generation of oxygen free radicals through the autoxidation of DOPA has been well documented (26-30). Further, Sotomatsu et al. (31) demonstrated that ferric ions significantly promoted peroxidative cleavage of unsaturated phospholipids in liposomes in vitro after coordinating with DOPA and dopamine, and that $\alpha$-TP and DF completely abolished the $\mathrm{Fe}^{3+}-\mathrm{DO}$ PA-induced lipid peroxidation, while SOD, catalase and sodium benzoate did not. Ceruloplasmin, a ferroxidase, also significantly inhibited the lipid peroxidation. Based on these results, they proposed that not oxygen free radicals, but rather oxene complexes such as $\mathrm{Fe}(\mathrm{V})=\mathrm{O}$ and/or $\mathrm{Fe}\left(\mathrm{IV}^{\top}\right)=$ $\mathrm{O}$ generated after further peroxidation would abstract hydrogen atoms from unsaturated phospholipids to initiate lipid peroxidation as a possible mechanism of $\mathrm{Fe}^{3+}$-DOPA-induced lipid peroxidation.

Interaction of iron with melanin could be another important trigger for neuronal cell death, because melanin avidly binds $\mathrm{Fe}^{3+}$ and reduces it to $\mathrm{Fe}^{2+}$, resulting in $\mathrm{O}_{2}(\cdot \mathrm{OH})$ generation (32).

$\mathrm{BPH}_{4}$ is the cofactor for monoamine oxygenase, which is involved in the biosynthesis of biogenic amines such as catecholamines, and is also a potent antioxidant $(15,16)$. In the present study, we examined the inhibitory effect of $\mathrm{BPH}_{4}$ on DOPA-induced cytotoxicity in PC-12 cells. First, the in vitro inhibitory potency of $\mathrm{BPH}_{4}$ on lipid peroxidation induced by $\mathrm{Fe}^{3+}$-DOPA complex was assessed by using PC-liposomes. The complex at $50 \mu \mathrm{M}$ or more caused drastic lipid peroxidation (Figure 1), though there was no significant difference among the 50, 100 and 200 $\mu \mathrm{M}$ treated groups. These findings are consistent with an earlier report (31). The lipid peroxidation induced by $50 \mu \mathrm{M} \mathrm{Fe}{ }^{3+}$-DOPA was significantly inhibited by $\mathrm{BPH}_{4}$ in dose-dependent manner (Figure 2 ). Other scavengers, DF and $\alpha-T P$, also suppressed the oxidation (Table I). Since tetrahydropterin was shown to stabilize iron (III) by weak complex formation (33), $\mathrm{BPH}_{4}$ may have a similar action, in addition to its antioxidant potency.

Next, we confirmed the in vitro potency of $\mathrm{BPH}_{+}$in cultured PC- 12 cells. Fe ${ }^{3+}$-DOPA complex increased LDH activity time- and dose-dependently (Figure 3), The elevation of this activity was also dose-dependently suppressed by $\mathrm{BPH}_{4}$ (Figure 4), which possessed almost the same potency as DF and $\alpha$-TP (Figure 5). $\mathrm{BPH}_{4}$ also inhibited DOPA-induced cytotoxicity, though as shown in Figure 6, much higher doses of DOPA were necessary to cause the same cytotoxic effect in PC- 12 cells as compared with $\mathrm{Fe}^{3+}$-DOPA complex. The toxicity was decreased markedly by SOD, and 
partially by catalase, while other scavengers were ineffective. Although the above results indicate that $\mathrm{O}_{2}$ and $\mathrm{H}_{2} \mathrm{O}_{2}$ mostly contribute to DOPA-induced cytotoxicity, other radicals may be involved. Basma et al (34) proposed that $\mathrm{O}_{2}$ and $\mathrm{H}_{2} \mathrm{O}_{2}$ are intermediates in the formation of the more toxic radical, $\cdot \mathrm{OH}$, via trace metal catalyzed Fenton- and/ or Haber/Weiss-type reaction. Another somewhat different hypothesis has also been proposed (35). In any event, it appears that the cytotoxicity induced by $\mathrm{Fe}^{3 *}$-DOPA and DOPA is due, for the most part, to the action of oxygen free radicals formed via autoxidation. Thus, the protective effect of $\mathrm{BPH} 4$ on both PC-liposomes and PC-12 cells against damage induced by DOPA with and without iron ion can be ascribed to the potent radical scavenging ability of $\mathrm{BPH}_{4}$. We consider that $\mathrm{BPH}_{4}$ is a potential therapeutic agent for Parkinson's disease through not only its potency to increase the supply of dopamine as a cofactor for hydrolases, but also its antioxidative potency.

1-Methyl-4-phenyl-1,2,3,6-tetrahydropyridine (MPTP) is a potent inducer of an animal model of Parkinson's disease. We have preliminarily examined the effect of $\mathrm{BPH}_{4}$ on MPTP-induced PC12 cell damage, and have already found that 1 methyl-4 phenylpyridinium (MPP+), which is considered as an ultimate active metabolite of MPTP, markedly induces PC-12 cell damage and $\mathrm{BPH}_{4}$ significantly protects the cells from this damage (data not shown). Further investigations are under way.

\section{Acknowledgments}

This work was supported in part by a Grant-inAid for Scientific Research (C) No. 07672426 from the Ministry of Education, Science and Culture, Japan.

\section{References}

1. Blau, N and Niederwieser, A. GTP crclohvdrolases: A review. J Clin. Chem. Clin. Biochem. 1985; 23 : 169-176.

2. Nichol, C.A., Smith, G.K. and Duch, D.S.: Biosythesis and metabolism of tetrahydrobiopterin and molvbdopterin. Ann. Rev. Biochem. 1985; 54: 729-764

3. Kaufman, S.: The structure of phenylalanine hydroxylation co-factor. Proc. Natl. Acad. Sci. U.S.A. 1963; 50: 1085-1093.

4. Shiman, R., Akino, M., and Kaufman, S., Solubilization and partial purification of tyrosine hydroxylase from bovine adrenal medulla. J. Biol. Chem. 1971; 246: 1330-1340.
5. Friedman, P.A., Kappelman, H., and Kaufman, S., Partial purification and characterization of tryptophan hydroxylase from rabbit hind brain. J. Biol. Chem. 1972; 247: 4165-4173.

6. Kwon, N.S., Nathan, C.F., and Stuehr, D.J., Reduced biopterin as a cofactor in the generation of nitrogen oxides by murine macrophages. J. Biol. Chem. 1989; 264: 20496-20501.

7. Werner-Felmayer, G., Werner, E.R., Hausen, A., Reibnegger, G., and Wachter, H., Tetrahydrobiopterin-dependent formation of nitrite and nitrate in murine fibroblasts. J. Exp. Med. 1990; 172:1599-1607.

8. Schmidt, K., Werner, E.R., Mayer, B., Wachter, H. and Kukovetz, W.R. Tetrahydrobiopterin-dependent formation of endothelium derived relaxing factor (nitric oxide) in aortic endothelial cells. Biochem. J. 1992; 281: 297-300

9. Kim, Y.M., and Lancaster, JR-Jr. Tetrahydrobiopterindependent nitrite oxidation to nitrate in isolated rat hepatocytes. FEBS Lett. 1993; 332: 255-259.

10. Keller, R, Bartholini, G., and Plescher, A., In vivo enhancement of tyrosine hydroxylation in rat stratum by tetrahydrobiopterin. Nature $1974 ; 249: 476-478$.

11. Curtius, H.C.H., Niederwieser, A., Levine, R., and Muldner, $H$., Therapeutic efficacy of tetrahydrobiopterin in Parkinson's disease. Adv. Neurol. 1984; 40: 463-466.

12. Koshimura, K., Miwa, S., Lee K., Fujiwara, M., and Watanabe, $Y$., Enhancement of dopamine release in vivo from the rat striatum. J. Neurochem. 1990; 54: 1391-1397.

13. Cohen, G., Oxygen radicals and Parkinson's disease. In: Oxygen Radicals and Tissue Injury, Halliwell B, eds. Bethesda FASEB 1988; 130-135.

14. Adams, J.D., and Odunze, I.N., Oxygen free radicals and Parkinson's disease. Free Radical Biol-Med. 1991; 10: 161-169.

15. Kojima, S., Ona, S., Iizuka, H., Arai, T., Mori, H., and Kubota, K., Antioxidative activity of $5,6,7,8$ tetrahydrobiopterin and its inhibitory effect on paraquat-induced cell toxicity in cultured rat hepatocytes. Free Rad. Res. 1995; 23: 419-430.

16. Kojima, S. Neo Neopterin as an endogenous antioxidant. Pteridines 1995; 6: 181-184.

17. Sugioka, K., and Nakano, M., Mechanism of phospholipid peroxidation induced by ferric ion-ADP-adriamycin coordination complex. Biochim. Biophys. Acta. 1982; 713: 333-343.

18. Gavino, V.C., Miller, J.S., Ikharebha, S.O., Milo, G. E., and Cornwell, D.G., Effect of polyunsaturated fatty acids and antioxidants on lipid peroxidation in tissue cultures. J. Lip. Res. 1981; 22: 763-769.

19. Forno, L.S., Pathology of Pakinson's disease. In: Movement Disorders, Marssden CD and Fahn S, eds. Butterworth Scientific, London: (1982).

20. Dexter, D.T., Carter, C., Agid, F., et al. Lipid peroxidation as a cause of nigral cell death in Parkinson's disease. Lancet 1986; 2: 639-640.

21. Sofic, E., Paulus, W., Jellinger, K., Riederer, P., and Youdim, M.B.H., Selective increase of iron in sub- 
stantia nigra zona compacta of parkinsonian brains. J Neurochem. 1991; 56: 978-982.

22. Dexter, D.T., Carayon, A., Agid, F., et al. Alterations in the levels of iron, ferritin and other trace metals in Parkinson's disease and other neuro-degenerative diseases affecting the basal ganglia. Brain 1991; 114: 1953-1975 (1991).

23. Ambani, L.M., Van Woet, M.H., and Murphy, S., Brain peroxidase and catalase in Parkinson's disease. Arch. Neurol. 1975; 32: 114-118.

24. Perry, T.L., and Yong, V.W., Idiopathic Parkinson's disease, progressive supranuclear palsy and gluthathione and metabolism in the substantia nigra of $\mathrm{pa}$ tients. Neurosci. Lett. 1986; 67: 269-274.

25. Riederer, P., Sofic, E., Rausch, W.D. et al. Transition metals, ferritin, glutathione, and ascorbic acid in parkinsonian brain. J. Neurochem. 1989; 52: 515-520.

26. Rosenberg, P.A., Catecholamine toxicity in cerbral cortex in dissociated cell culture. J. Neurosci. 1988; 8: $2887-2894$

27. Michel, P.P., and Hefti, F., Toxicity of 6-hudroxydopamine and dopamine for dopaminergic neurons in culture. J. Neurosci. Res. 1990; 26: 428-435.

28. Ogawa, N., Edamatsu, R., Mizukawa, K., Asanuma, M., Kohno, M., and Mori, A., Degeneration of dopaminergic neurons and free radicals: possible participation of levodopa. Adv. Neurol. 1993; 60: 242250 .

29. Ben-Shachar, D., and Youdim, M.B.H., Intranigral iron injection induces behavioral and biochemical "parkinsonism" in rats. J. Neurochem. 1991; 57: 2133 2135.

30. Jellinger, K., Kienzl, E., Rumpelmair, G. et al. Ironmelanin complex in substantia nigra of Parkinsonian brain: An X-ray microanalysis. J. Neurochem. 1992; 59: 1168-1171

31. Sotomatsu, A., Nakano, M., and Hirai, S., Phospholipid peroxidation induced by the catechol- $\mathrm{Fe}^{3 .}$ $\left(\mathrm{Cu}^{2+}\right)$ complex: a possible mechanism of nigrostrial cell damage. Arch. Biochem. Biophvs. 1990; 283 : 334-341.

32. Hintz, P., and Kalyanaraman, B., Metal ion-induced activation of molecular oxygen in pigmented polymers. Biochim. Biophys. Acta. 1986; 883: 41-45.

33. Schäfer, A., Fischer, B., Bosshard, R., Hesse, M. and Viscontini M: Formation of FeIII or FeII complexes with acetylacetonate and 5,6,7,8-tetrahydropterin as ligands and their activation of oxygen. In Chemistry and Biology of Pteridines and Folates, Ayling JE, Nair MG and Baugh CM, eds. New York; Plenum Press, $1993 ; 29-32$.

34. Basma, A.N., Morris, E.J., Nicklas, W.J., and Geller, H.M., L-DOPA cytotoxicity to PC 12 cells in culture is via its autoxidation. J. Neurochem. 1995; 64: 825-862.

35. Olney, J.W., Zorumski, C.F., Stewart, G.R., Price, M T., Wang, G., and Labruyere, J., Excitotoxicity of LDOPA and 6-OHDOPA: implications for Parkinson's and Huntington's diseases. Exp. Neurol. 1990; 108: 269-272. 